photographed from a point of view approximating that in the engraving. The intact summit at the centre of the image and the angle between the upper two cube faces enclosed by the visible edges differ conspicuously from the Melencolia solid (Fig.2).

Max Steck, thinking it might be a modified octahedron, enlisted the gemologist Paul Grodzinski to construct a model of the solid. Starting with the plane figure of eight identical equilateral triangles from which the octahedron develops, Grodzinski reduced the size of two opposing faces and redrew the others as identical five-sided polygons. When this plane figure was cut out and folded, the resulting solid resembled the Melencolia body but was too slender. A cube he constructed with opposed summits truncated by equilateral triangles was too oblique. For his third trial, he drew five-sided plane figures with apical angles of $72^{\circ}$ ('as the angle of $72^{\circ}$ is connected with the polygon') and obtained a solid more closely resembling the artist's image. The key to creating the solid was 'the point angle used by Durer', he reported. 'This is offered as a solution to the question of what the geometric body in Durer's Melencolia represents'9. When an edge model with these apical angles (and opposed diagonals equal to those of the cube above) was constructed and photographed from the same distance, the edges and internal angles of the resulting image approximated those in the engraving (fig.3).

Although Durer's sketch for the figure did not detail the steps by which he constructed it, for his treatise on measurement he drew the plane figure from which develops a tetrahedron truncated by an opposing one of different size ${ }^{10}$. This shows that he had apprehended one of the geometrical properties of the octahedron, in which two identical tetrahedra are symmetrically opposed. Another diagram shows that he realized that the summits of a cube can be truncated equally by the faces of an octahedron. If only two summits are altered in any perfect solid, its other axes of symmetry are lost and its spatial logic is destroyed $^{11}$.

Attribution of meanings to the manifestations of culture is a subjective process. Panofsky has persuasively argued that the history of art is a humanistic discipline because that is what it seeks to do ${ }^{12}$. When the Melencolia body is regarded as a geometrical problem, without reference to what it might mean but simply what solid it represents, we may specify that the solution would be a figure that could be truncated by equilateral triangles without losing its spatial logic. This could only be a trigonal solid exhibiting threefold rotational symmetry. The geometrical figure that meets this condition is the rhombohedron, which can be truncated on its principal axis without losing its rotational symmetry. Since two visible summits are oblique, the terminations removed would

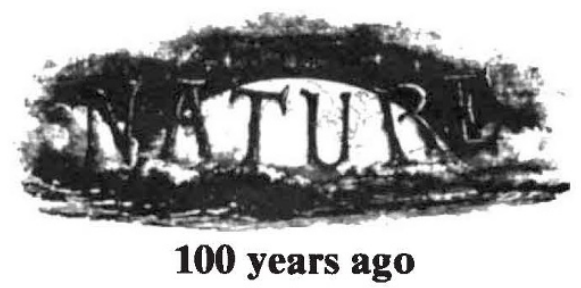

\section{THE THIRST FOR SCIENTIFIC RENOWN}

FEW students of science can fail to feel at times appalled by the ever-increasing flood of literature devoted to science and the difficulty of keeping abreast of it even in one special and comparatively limited branch of inquiry. Were merely the old societies and long established journals to continue to supply their contributions, these, as they arrive from all parts of the country, and from all quarters of the globe, would be more than enough to tax the energy of even the most ardent enthusiast. But new societies, new journals, new independent works start up at every turn, till one feels inclined to abandon in despair the attempt to keep pace with the advance of science in more than one limited department.

be less than right angles. The figure may thus be identified as a truncated acute rhombohedron.

A crystallographer, Charles Bunn ${ }^{13}$, wrote that the Melencolia body was 'like an enormous crystal .... challenging the human onlooker by the precision and symmetry of its form' (without suggesting its identity). Durer seems to have had some intuition of the symmetry properties of the body since he invited comparison of the polyhedron to the sphere below it in the composition. The sphere exhibits perfect rotatory symmetry while the sleeping $\mathrm{dog}$, even though it curls in a circle, has none. Not until almost three centuries later would naturalists observe that the mineral calcite, when it takes the form of the acute rhombohedron in crystals familiarly known as dog-tooth spar, sometimes occurs in truncated examples without loss of symmetry ${ }^{14}$. Some of these are less acute than that in Fig. $3^{15}$. The failure of art historians to establish the geometric identity of the figure has allowed them to overlook one of the dramatic qualities of the work, that the artist knew the answer to the puzzle that perplexes the heroine of the engraving ${ }^{16}$. An historian of chemistry and alchemy suggested that it might be the 'image of the philosopher's stone or . . . of that so-called 'Stone of Saturn' ' in some ritual ${ }^{17}$. It would be more fitting to credit Albrecht Durer with anticipatory intuitions about the science of descriptive geometry established long after his death. What appears in this remarkable work of art is that by 1514 magic had lost its grip on the educated mind ${ }^{18}$.

Philip C. Ritterbush is Program Director in the Institute for Cultural Progress, 2913 29th Street $N W$, Washington, $D C$.
One of the most striking and dispiriting features of this rapidly growing literature is the poverty or worthlessness of a very large part of it. The really earnest student who honestly tries to keep himself acquainted with what is being done, in at least his own branch of science, acquires by degrees a knack of distinguishing, as it were by instinct, the papers that he ought to read from those which have no claim on his attention. But how often may he be heard asking if no means can be devised for preventing the current of scientifc literature from becoming swollen and turbid by the constant inpouring of what he can call by no better name than rubbish!

Some sciences seem to be specially exposed to inundation of this kind. Geology lies exposed to it in an unusual degree. Popular in its subject, and capable of ready apprehension as to its general principles, this department of science allures the outsider into its precincts, where he too frequently soon arrives at the belief that to have read a geological book or two is to become a geologist. This belief would be harmless enough, did it not speedily bear fruit in "papers" communicated to scientific journals, and stamped with all the enthusiasm and crudity of a beginner.

From Nature 27, 285; January 25; 1883.
I. Steck, M. Actes du dixième Congrès International d'Histoire des Sciences 1, 655 (Hermann, Paris, 1963); Nova Acta Leopoldina, NF 16, 425 (1954).

2. Steck, M. Forschn Fortschr. 32, 246 (1958).

3. Barlow, Sir T.D. The Medieval World Picture \& Albrecht Dürer's Melencolia (Roxburghe Club, Cambridge, 1950).

4. Wolfflin, H. The Art of Albrecht Durer, 1905 (trans. Grieve, A. \& H.) (Phaidon, London, 1971).

5. Strauss, W.L. The Complete Engravings, Etchings and Drypoints of Albrecht Dürer (Dover, New York, 1972).

6. Strauss, W.L. The Human Figure; the Complete 'Dresden Sketchbook' (Dover, New York, 1972).

7. Ivins, W. Jr On the Rationalization of Sight, with an Examination of Three Renaissance Texts on Perspective (Metropolitan Museum of Art, New York, 1938).

8. Klibansky, R., Panofsky, E. \& Saxl. F. Saturn and Melancholy; Studies in the History of Natural Philo sophy, Religion, and Art (Basic Books, New York, 1966).

9. Grodzinski, P. Ind Diam. Rev. 15, 66, 87 (1955).

10. Durer, A. Underweysung der Messung ... (for the author Nürnberg, 1525); Steck, M. Dürers Gestaltlehre der Mathematik und der bildende Kanste (Niemeyer Halle, 1948) on mentals of Three-dimensional Descriptive Geometry mentals of Three-dimensional Desc
2nd edn (Wiley, New York, 1976).

11. Shubnikov, A.V.\& Kptsik, V.A. Symmetry in Science and Art (trans. Archard, G.D.) (Plenum, New York, 1974) Phillips, F.C. An Introduction to Crystallography (Longmans, London, 1946), defined crystal 'form' as 'the assemblage of faces necessitated by the symmetry when one face is given'. See Fig.15, a truncated obtuse rhombohedron, cited in ref. 9 .

12. Panofsky, E. 'The History of Art as a Humanistic Discipline' in Meaning in the Visual Arts (Doubleday, New York, 1955)

13. Bunn, C. Crystals; Their Role in Nature and Science (Academic, New York, 1964).

14. Jacques-Louis, Comte de Bournon Traité Complet de la Chaux Carbonatée et de l'Arragonite, Fig.156 (Phillips, London, 1808).

15. Goldschmidt, V. Allas der Krystallformen (Winter, Heidelberg, 1913); Tafeln 2, PI.3, Fig.16 (after Ha0y); Heidelberg, 1913); Tafeln 2, Pl.3. Fig.16 (after Hally);
Whitlock, H. Calcites of New York, Pl.14 (York State Museum, Albany, 1910).

16. Nagel, F.A. Der Kristall auf Diurers Melancholie (Koch, Nurnberg, 1922); for a correct identification of the figure see Weber, P. Studien zur deutschen Kunstgeschichte 23 (1900).

17. Read, J. Through Alchemy to Chemistry (Bell, London, 1957).

18. Debus, A.G. The Chemical Philosophy; Paracelsian Science and Mathematics in the Sixteenth and Seventeenth Centuries (Science History Publications, New York, 1977); Ritterbush, P. Proc. biol. Soc. Wash. 82, 561 (1969) and in Art and Science in the Renaissance (eds Hoeniger, D. \& Shirley, J.) (Princeton University Press, in the press). On symmetry in Renaissance painting, see Summers, D. The Art Q. 1, 59 (1977); Smithson, $R$. in The Writings of Robert Smithson (ed. Holt, N.) (New York University Press, 1979). 